\title{
How Can Landscape Architecture Influence Systemic Change to Achieve Sustainable Cities and Regions
}

\author{
By Anastasia Nikologianni ${ }^{*}$
}

This paper presents how the ideas of landscape, design quality and drawings can influence systemic change to result in sustainable cities and regions. The research related to this paper explores project frameworks and design methods in order to reveal innovative ways and processes for creating environmentally friendly cities and regions that will have the power to adapt and mitigate climatic issues of the future. Through a series of explorations on existing landscape projects and while using a series of stakeholder engagement workshops contacted at a pan-European level the paper examines ways in which systemic change is possible and the outcomes it has in relation to the landscape. Using previously implemented and ongoing landscape projects such as the Room for the River (the Netherlands) and the West Midlands National Park (UK), the paper discusses how bold landscape-led visions influence decision making and support systemic change on a spatial scale. Drawing on experience gained during a series of stakeholder engagement workshops, where the projects of the Tame Valley Wetlands Partnership (UK) and the Urban Farming and Growing Network (UK) were selected as case studies, the research presents key findings and presents lessons learned that can build capacity and improve the understanding and management of stakeholders when it comes to spatial planning and urban design. The paper argues that a new way of thinking in design, policy or governance is not enough if these disciplines act individually. The breakthrough comes when each discipline collaborates with the aim to future proof our cities and regions. By presenting pioneering examples and models giving us tools for a systemic change, the paper aims to demonstrate that large scale developments can be brilliant examples of the new methodologies applied and lessons learnt. This research concludes that systemic change is represented across all levels, policy, decision making, governance, design and implementation if the aim is to deliver a sustainable city.

\section{Introduction}

This paper uses a series of innovative workshops and pioneering project frameworks to explore the significance of landscape design and the ways in which this can influence systemic change at a city and regional level. Using the process from two strategic landscape schemes, the Room for the River in the Netherlands and the West Midlands National Park in the UK, the paper aims to discuss key elements, such as design, policy, decision making and governance, that need to be in place in order to support systemic change. In addition to presenting two case studies from the pan-European project EIT Climate-KIC SATURN, the Tame Valley Wetlands and the Urban Farming and Growing Network (both in the UK),

*Post Doctoral Research Fellow, School of Architecture and Design, Birmingham City University, UK. 
the paper indicates that stakeholder engagement and communication also play a significant part when it comes to large-scale landscape projects and the way they can transform the planning and decision making processes.

Cities and regions are believed to be a significant part of the "climate crisis puzzle" and their significant contribution needs to be assessed if we are to address the various environmental and social challenges to achieve sustainability and resilience on a large scale. For this to be materialized though, design principles need to take part in the territorial transformation processes. ${ }^{1}$ As von Wirth et al. ${ }^{2}$ suggest, cities are increasingly experimenting in response to climate crises, exploring new methods and attempting to be innovative. However, at a large scale, we have not yet witnessed a consistent pattern of transformation, so this paper suggests that for such a spatial transformation a systemic change is crucial. Masson $e t \mathrm{al}^{3}$ argue that even though several studies have investigated cities and the change of climatic behaviour, none has "allowed the city to change (either in form or function)", revealing that the issue is not the identification of new processes and technologies, but how to apply them to transform both the shape and operational system of an area. The focus of this paper is to demonstrate how landscape design and planning can support a behavioural and systemic transformation as well as extract key elements from pioneer schemes on how this has been proven possible.

Using innovative models that have integrated a holistic landscape vision, this paper presents and analyses how crucial parts of a landscape project, such as design and policy, governance and decision making, become the key parts to transform a system and its processes. In addition, with the help of stakeholders and real-life schemes, the importance of stakeholder engagement and communication is being revealed when it comes to behavioural change and delivery. The paper suggests that all these elements are necessary and the negligence of one or another can cause the system transformation to fail, leading to potentially another inspirational plan or vision not being successfully implemented.

\section{Systemic Change and Environmental Challenges}

Systemic change occurs when change reaches all or most parts of a system, thus affecting the general behaviour of the entire system. This broad definition can apply to any system, therefore in the spatial context of planning and landscape design, the system consists of all the relevant actors that are involved, from the designers to the decision makers, civil servants and also users of the area. Studies have been conducted on the importance of systemic change as well as the meaning

1. S. Nijhuis and D. Jauslin, "Urban Landscape Infrastructures. Designing Operative Landscape Structures for the Built Environment," Research in Urbanism Series 3 (2015): 13-34.

2. T. von Wirth, L. Fuenfschilling, N. Frantzeskaki and L. Coenen, Impacts of Urban Living Labs on Sustainability Transitions: Mechanisms and Strategies for Systemic Change Through Experimentation,” European Planning Studies 27, no. 2 (2019): 229-257.

3. V. Masson, C. Marchadier, L. Adolphe, R. Aguejdad, P. Avner, M. Bonhomme, et al., "Adapting Cities to Climate Change: A Systemic Modelling Approach," Urban Climate 10 (2014): 407-429. 
or interpretation of a sustainable city and region, however there is not much coherence on how cities can achieve systemic change and the benefits of spatial planning in such initiatives. As Angheloiu and Tennant ${ }^{4}$ state, "although academic-led literature advocates for systemic change towards sustainability as an outcome of a diverse palette or urban interventions, less consideration is given to the means and enablers for achieving these". Therefore, this paper's focus is to present and analyse the means and key elements to achieve systemic change in a spatial context.

Several studies examining the sustainability transitions indicate that "we are facing persistent systemic problems - often referred to as grand challenges such as climate change, biodiversity loss, resource depletion and social inequalities - that neither individual technological solutions nor individual policy instruments can effectively solve."5 Our cities and regions are constantly under threat with environmental phenomena becoming more often and more severe. As a result of the continuous environmental changes and the climate crisis, Bai explains that by 2030 millions of people will be at risk from climate related events, such as floods, wildfires, heavy rains, mudslides and drought. ${ }^{6}$ Emphasizing the vulnerability of cities and urban centres, Bulkeley states that "cities are central to the ways in which the vulnerabilities and risks of climate change are produced and to the possibilities and challenges of responding to these issues."7 As Ostberg et al. state, our landscapes will also face big changes related to the change of climate ${ }^{8}$ and therefore we need to focus on cross-silo solutions rather than focusing on individual perspectives of each discipline. Even though scientists have started recognizing cities as complex systems and turn their focus on communities and wellbeing, there is still no strong evidence of coherent cross-silo approaches. It is now apparent that we have been ignoring nature and natural processes with regards to our cities and communities, and that this has resulted in several challenges, of increasing severity, for our urban centres, economies and our health. As Bai points out, the lack of long-term studies of urban climates, their impacts as well as the focus on single disciplines research funding and 'business as usual' approaches provide little scope for cross disciplinary projects, ${ }^{9}$ a fact that creates great difficulty to the establishment of a holistic approach for a whole city or region based on its landscape, urban characteristics and community. In addition, the literature mentions that "infrastructure over the last centuries was in service of

4. C. Angheloiu and M. Tennant, "Urban Futures: Systemic or System Changing Interventions? A Literature Review Using Meadows' Leverage Points as Analytical Framework," Cities 104 (2020): 102808.

5. L. Gorissen, F. Spira, E. Meynaerts, P. Valkering and N. Frantzeskaki, "Moving Towards Systemic Change? Investigating Acceleration Dynamics of Urban Sustainability Transitions in the Belgian City of Genk," Journal of Cleaner Production 173 (2018): 171-185.

6. X. Bai, R. J. Dawson, D. Ürge-Vorsatz, G. C. Delgado, A. S. Barau, S. Dhakal, et al., "Six Research Priorities for Cities and Climate Change," Nature Publishing Group 555 (2018): 23-25.

7. H. Bulkeley, Cities and Climate Change (Abigdon: Routledge, 2013).

8. S. Ostberg, S., L. R. Boysen, S. Schaphoff, W. Lucht and D. and Gerten, "The Biosphere under Potential Paris Outcomes," Earth's Future 6 (2018): 23-39.

9. Bai, Dawson, Ürge-Vorsatz, Delgado, Barau, Dhakal, et al., "Six Research Priorities for Cities and Climate Change," 2018. 
the conquest of nature, whereby the environment was denied its natural dynamism in favour of more controlled and static systems." system cannot be addressed in silos, either related to urban infrastructures or technical challenges. As Wolfram et al. remarks "system change is almost exclusively addressed by STS [socio-technical system] studies concerned with urban infrastructures, thus still reflecting the original focus on sectoral (national) STS and relative disregard of the role of place."11

Looking into how a transition can be achieved in urban centres, Masson et al. explain that "if cities are to be adapted to the projected future climate, it is necessary to start adaptation now by modifying city structure, building design, urban planning habits etc.," $" 12$ but this research also argues more than that is needed. A wider change in the way in which the systems and processes operate is essential and it is also a matter of behavioural change both for the citizens as well as the decision makers. Cities and regions need to concentrate their focus on achieving the goals of global policy frameworks ${ }^{13}$ in response to the climate crisis while they focus on a response to zero-emissions, net zero routes and zero-waste solutions. As Anghelou and Tennant explain, urban sustainability is often interpreted as "urban ecology", "eco-city", "low-carbon city" or "green" city, ${ }^{14}$ but what this paper seeks to understand is how we achieve this at a city or regional scale. What are the necessary steps and processes that lead to a true low carbon city and what changes are required in the governance and decision-making processes? It is suggested that society often tries to respond to environmental challenges in a way that guarantees 'business as usual' without major alterations in our lives, ${ }^{15}$ but perhaps we need to consider that behavioural changes are unavoidable at this stage if we are to future proof our cities and regions. The society is at a stage where a transition to sustainable cities and methods is essential and as Gorissen et al. ${ }^{16}$ state, this is defined as "a radical transformation towards a sustainable society, as a response to a number of persistent problems confronting contemporary modern societies. As such, it brings about fundamental change in the ways of thinking (cultures), ways of organizing (structures) and ways of doing (practices) that unfold in phases with different distinct dynamics". As argued by Papa et al. the "first step is shifting from current silo approaches towards a systemic

10. S. Nijhuis, D. Jauslin and C. De Vries, Flowscapes: Infrastructure as landscape, landscape as infrastructure. Graduation Lab Landscape Architecture 2012/2013 (Delft, The Netherlands: Delft University of Technology, 2012).

11. M. Wolfram, N. Frantzeskaki and S. Maschmeyer, Cities, systems and sustainability: status and perspectives of research on urban transformations." Current Opinion in Environmental Sustainability 22 (2016): 18-25.

12. Masson, Marchadier, Adolphe, Aguejdad, Avner, Bonhomme, et al., "Adapting Cities to Climate Change: A Systemic Modelling Approach," 2014.

13. Angheloiu and Tennant, "Urban Futures: Systemic or System Changing Interventions? A Literature Review Using Meadows’ Leverage Points as Analytical Framework,” 2020.

14. Ibid.

15. I. Blühdorn, "Sustaining the Unsustainable: Symbolic Politics and the Politics of Simulation," Environmental Politics 16, no. 2 (2007): 251-275.

16. Gorissen, Spira, Meynaerts, Valkering and Frantzeskaki, "Moving Towards Systemic Change? Investigating Acceleration Dynamics of Urban Sustainability Transitions in the Belgian City of Genk," 2018. 
one," ${ }^{17}$ as this could support multidisciplinary work and cross-sectoral strategies, dealing effectively with interconnected challenges. This paper agrees with this approach and aims to present innovative projects that have indicated best practices towards systemic change in a spatial context.

\section{Methodology}

This paper explores ways in which systemic change has been introduced and implemented in urban and regional landscape schemes. Examination of innovative schemes aim to assess whether a system's change is possible and the outcomes it has in relation to our communities, wellbeing and future of our cities. The methodology is based on close examination of implemented and ongoing landscape-led projects such as the Room for the River (the Netherlands), the West Midlands National Park (UK), and the Tame Valley Wetlands (UK) and Urban Farming and Growing Network (UK) case studies from the EIT Climate-KIC SATURN pan-European project. Exploration and evaluation of these strategic schemes focus on the identification of key stages in the process of a system's change that cannot be avoided or overlooked in order to transition to sustainable cities and regions.

The methodology includes an in-depth analysis of the projects' structures, the process followed and the changes in governance and management. It has been conducted at the various project locations including workshops, observations, interviews with experts, field visits, and activities with local stakeholders. The methodological process developed for this paper looks at the selected projects from a different lens to a prior investigation that had focused on ways in which such projects had been integrating qualities such as "sense of place" and "environmental principles". The methods used in this paper, examined the projects based on their achievements on behavioural and systemic change and their outcomes in the different regions. After the initial research, results indicated that systemic change actions shall be separated into three key stages of a. Achieving systemic change through design and policy, b. Achieving systemic change through decision making and governance and c. Achieving systemic change through stakeholder engagement and communication. Each stage is equally important, however, some of the examined landscape cases, have more powerful examples and therefore this paper uses them to communicate the importance of each stage in relation to landscape schemes.

The data collected for this paper is based on stakeholder engagement workshops, meetings and policy roundtables with decision makers, visuals and observations. Case study and workshop notes, drawings and images of sustainable approaches, maps, policy and technical documents, as well as outputs from the stakeholder workshops were collected and analysed through content analysis.

17. R. Papa, A. Galderisi, M. C. Vigo Majello and E. Saretta, "Smart and Resilient Cities. A Systemic Approach for Developing Cross-Sectoral Strategies in the Face of Climate Change," TeMA Journal of Land Use, Mobility and Environment 8, no. 1 (2015): 19-49. 


\section{Achieving Systemic Change in Large-Scale Landscape Projects}

The report of the results of this empirical analysis is as follows. This section describes and analyses the different strategies observed that facilitated the embedding of; key actions, the processes and outcomes of systemic change for each examined project. Each of these projects is likely to have more than one or all of the key stages identified, however for the purposes of this paper the author focuses on the most crucial stage from each scheme in order to effectively demonstrate its importance in achieving systemic change.

\section{Design and Policy: Achieving Systemic Change (Room for the River)}

The whole Room for the River programme (the Netherlands) is about re-defining the way we have learned to deal with water. It is about using skills and experience to design places where water is enhanced, valued and appreciated without losing any of the social or economic benefits of the area. The Room for the River (RftR) is a national-scale climate adaptation programme ${ }^{18}$ that was intended to form sustainable ways of dealing with rising sea levels in the country and make more room for its various rivers. Based on an innovative design and management process, the programme ensured a high level of protection against rising water levels in 34 project locations across the Netherlands, while introducing several design and policy elements that led to a significant change of processes and behaviours in the region. To achieve behavioural and systemic change, practitioners cannot infuse separate elements in an area and expect them to work collectively, a vision is needed for the whole region, and design needs to drive this vision as demonstrated by the RftR. The planning and design process needs to put the landscape at the core of any development. "Design thinking should be a part of creating the vision and designing the brief of a new project" clearly states the Design Council, ${ }^{19}$ but as implementation shows through the RftR, policy is an important step for the successful delivery of this design. ${ }^{20}$ This pioneering scheme managed to achieve systemic change in the Netherlands by working on ideas on the regional as well as the local scale and continuously addressing challenges across all levels. As the materialization of a project cannot be successful if the large and local scale are not coherent, similarly such a system cannot be changed only from a bottom up or top down approach. One of the key outcomes of the RftR programme, in relation to the focus of this paper, is that a system requires transformation from both sides, on a macro as well as a micro level.

The role of landscape design is key from the conceptual stage to delivery of the RftR, demonstrating that design and drawings can convey messages in a much

18. D. Sijmons, Y. Feddes, E. Luiten, F. Feddes, M. Nolden and J. Bosch, Room for the River: Safe and Attractive Landscapes (The Netherdlands: Blauwdruk, 2017).

19. Design Council, A Design-Led Approach to Infrastructure (Cabe, 2012).

20. A. Nikologianni, The Role of Low Carbon, Spatial Quality and Drawings in LandscapeBased Regional Strategies (Birmingham, U.K.: Birmingham City University, 2018). 
more effective way than documents or text ${ }^{21}$ and therefore design is much more likely to be the forerunner of new ideas and transitions as it enhances aspirations and visions. Figure 1 is one of the visuals used for the RftR project location of Noordwaard and its goal was to communicate the broader vision for the project. Based on the flood plain the Noordwaard RftR project was proposing the recreation of wetland areas, boat and cycling routes, contemplation spots and a nature reserve for the region. However, this achievement needed to overcome the current flood infrastructure, water policies and most importantly needed to alter the mindset and way of living of the nearby community which was mainly consisted of farmers and breeders. The success was not only in completing the project, but delivering a new way of interacting with water, a way that would give more room to the local river Nieuwe Merwede. As a result of its effective implementation, the Noordwaard RftR project is perceived, by this research, as a successful demonstration of many systemic processes as well as behavioural transformations. The challenges were many, from physical and technical issues to habits and traditional ways of living. However, this pioneering design has promoted the creation of new ideas as well as increased communication towards a systemic change in the area.

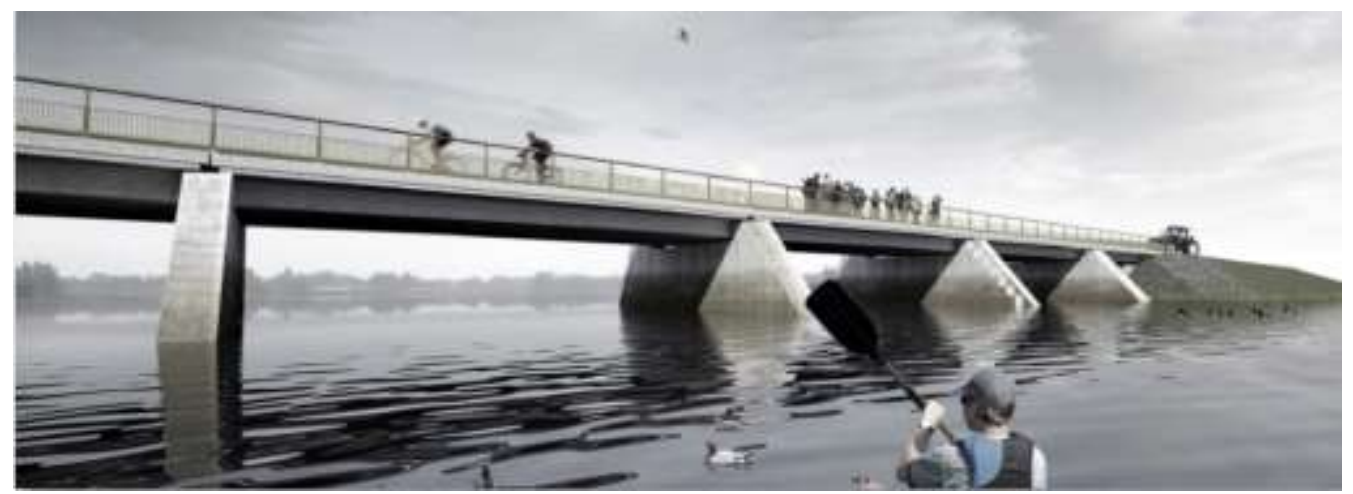

Figure 1. Design Drawing from Noordwaard, Room for the River Programme Image Courtesy: Rijkswaterstaat, Room for the River.

Another example is the Citadel Bridge in Nijmegen (Nijmegen project, part of the RftR). Even though this is only one element of a very large urban scheme, it has managed to connect concept, design, as well as behavioural change. The Citadel Bridge (Figure 2) is a mixture of design and policy innovations. As presented in Figure 2, when the water levels are normal then pedestrians and cyclists can use the wide part of the bridge, but when water levels rise, pedestrians can only walk on the narrow stepping-stones. It might initially seem as a simple design trick, however this paper suggests that by "forcing" someone's body to use the stepping stones, it alerts their mind to understand the change and adapt to it. It is a step towards greater awareness and behavioural change. Observations show that the Citadel Bridge has a pioneering design that allows the commuters to engage with water, but it has also overcame several policy issues related to safety and

21. A. Nikologianni, K. Moore and P. J. Larkham, "Making Sustainable Regional Design Strategies Successful,” Sustainability 11, no. 4 (2019): 1-20. 
standardization. Therefore, using this evidence, this research argues that to achieve systemic change both a bottom up and a top down approach are needed. We need the bottom up approach, the public to understand, residents and visitors to appreciate an area, designers and engineers to go at great lengths to deliver new ideas, but we also need the top down approach. We need policy and legislation to support these initiatives, to make sure elements of sustainability, resilience, climate adaptation and mitigation are being delivered on the ground.

The RftR has been chosen by this paper to demonstrate why design is so significant for a systemic change. It is one living example, of behavioural and systemic change in the spatial environment both in urban and rural scales. But it has also revealed that a system change in spatial and large scale requires continuous support from policy and legislation as well as inspirational design initiatives.

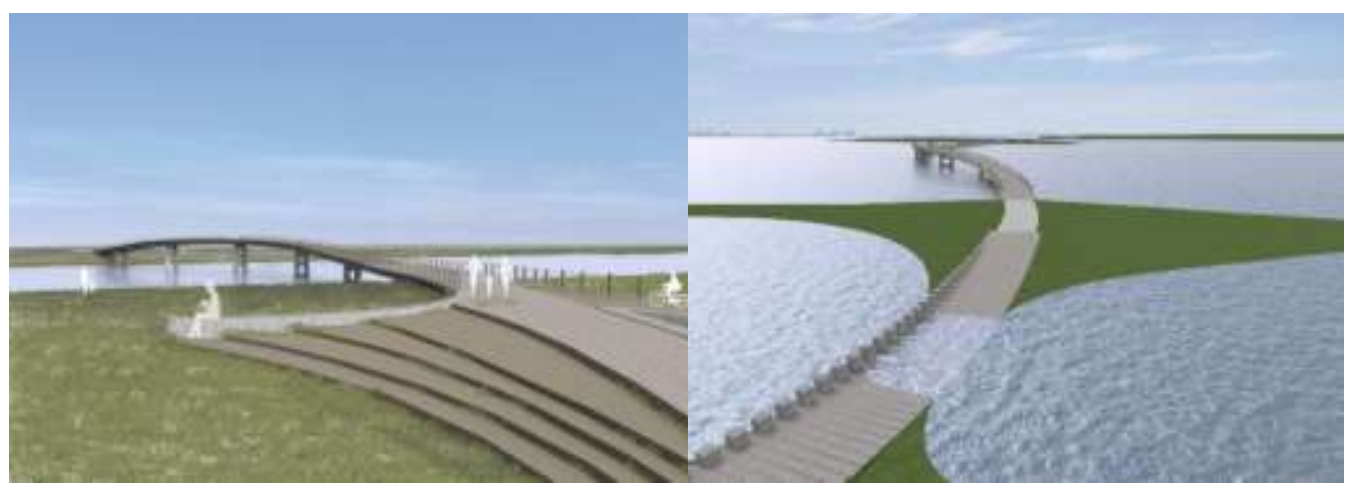

Figure 2. Visual Drawings of the Citadel Bridge in Nijmegen, Room for the River Programme

Image Courtesy: Rijkswaterstaat, Room for the River.

\section{Decision Making and Governance: Achieving Systemic Change (WMNP)}

The West Midlands National Park (WMNP) proposal developed by the CATiD research centre at Birmingham City University offers a broad vision that sets the basis for a greener recovery in the area of the West Midlands, UK. Using visuals and drawings to understand and evaluate the landscape, the proposal aims to create a strong landscape identity for the region and to demonstrate the value of the landscape, the environment as well as the social and cultural elements of the area. The WMNP proposal is based on cross boundary and multidisciplinary approaches and focuses on the relationship communities have with their surrounding landscapes. It examines a new idea of a National park, "embracing the ambition of UK Government's DEFRA 25-year plan,"22 with a new approach on how a whole region can be regenerated and sets goals for a more sustainable future, without losing out on economic or social benefits.

Even though this is an ongoing proposal, it has been instrumental in raising aspirations for the region. Having been adopted as the drive behind the West Midlands green economic recovery from COVID-19 and being the force to help

22. S. Consortium, SATURN Conference, Workshop, Exhibition. K. Moore and A. Nikologianni (Birmingham, U.K.: Birmingham City University, 2019). 
achieve a heathier, more inclusive region ${ }^{23}$ the WMNP is evidence that landscape design plays a crucial part on the decision making and governance processes when it comes to systemic change. With the use of a series of powerful drawings and visuals, numerous workshops and lots of high-level discussions, the WMNP has demonstrated, that decision making on a strategic scale requires a deeper knowledge of the area. The powerful diagrammatic drawings (Figure 3) are intentionally designed to focus on the large instead of the small scale, allowing for the significant morphological, environmental and social elements (e.g., rivers, valleys, geology, historical sites, views) to be presented. These influential drawings are becoming a strong communication tool revealing new ideas and approaches that truly influence governance and decision making.

Cities are possibly the most affected, but also the most privileged to adapt to the climate crisis, however a significant part of their planning system is their decision making and governance mechanism and therefore if they are to address the climate challenges we face, a new way of making decisions, with criteria based on the value of landscape and healthier communities is of major importance. As Dreier et al. mention "system change initiatives must be grounded in knowledge and insight about how the system functions" 24 and therefore one wonders if the right approach at a strategic level is to redefine and re-evaluate the system from the inside, while seeking support from pioneering external approaches and experts in the field of strategic visioning.

The West Midlands Combined Authority (WMCA) is using the WMNP as the vehicle towards the transition to a net zero carbon future and resilience ${ }^{25}$ basing on its success the possibility to open up new opportunities for the region and to change peoples' perceptions. The WMNP has demonstrated that landscape design can be a driving force in the way we evaluate our surroundings and make decisions for the future of our cities and regions. A true systemic change on a regional level cannot be achieved if the governance mechanisms are not reevaluated with a focus on resilience, climate adaptation and mitigation as well as public wellbeing. The WMNP proposal explored by this paper offers an innovative approach that can be beneficial across the globe, and the initial evidence gathered from the West Midlands region are encouraging that such an approach can transform the governance processes in place, in cases where design and landscape are seen as the core of any future development for that area.

23. WMCA, WMCA Signs up to West Midlands National Park (West Midlands, U.K.: WMCA, 2020).

24. L. Dreier, D. Nabarro and J. Nelson, Systems Leadership for Sustainable Development: Strategies for Achieving Systemic Change (USA: Harvard Kennedy School, 2019).

25. WMCA, WMCA Signs up to West Midlands National Park, 2020. 


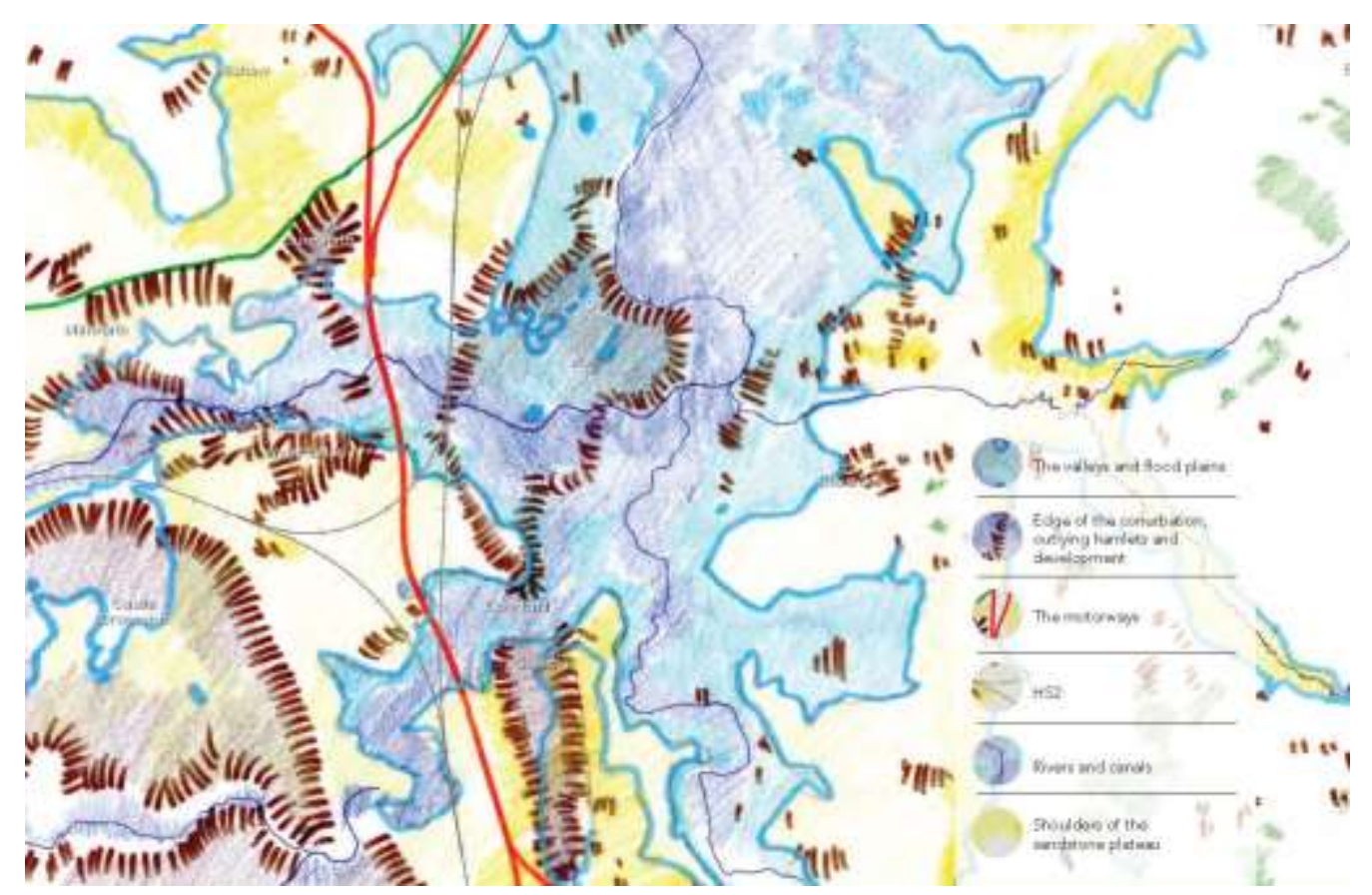

Figure 3. Diagrammatic Drawing Focusing on the Tame Valley, West Midlands Image Courtesy: Professor Kathryn Moore.

Stakeholder Engagement and Communication: Achieving Systemic Change (Tame Valley Wetlands \& Urban Farming and Growing Network)

SATURN is an EIT Climate-KIC pan-European collaborative project which deals with landscape fragmentation in urban and peri-urban areas. A collaboration between Italian, Swedish and UK organizations which aims to support cities to address their challenges in relation to the climate crisis, food production and landscape management. ${ }^{26}$ For the purposes of this paper, the author focuses on the ways in which cities operate as well as the interaction of various stakeholders involved in order to achieve holistic transformation in the region. The paper explores two case studies conducted by SATURN in the UK, the Tame Valley Wetlands (TVW) and the Urban Farming and Growing Network (UFGN) examining the importance of communication and a rigorous stakeholder engagement process as the pathway towards systemic change.

Cities and regions are perceived as innovation systems, contested sites of implementation or seedbeds for a transition to new behaviours and methods ${ }^{27}$ and therefore the way in which their key actors will respond to change is of great relevance for the overall result of the city's system transformation. Dreier et al. also explain that "complex systems are viewed, understood or experienced

26. A. Nikologianni, A. Betta, A. Pianegonda, S. Favargiotti, K. Moore, N. Grayson, et al., "New Integrated Approaches to Climate Emergency Landscape Strategies: The Case of PanEuropean SATURN Project," Sustainability 12, no. 20 (2020).

27. Wolfram, Frantzeskaki and Maschmeyer, "Cities, Systems and Sustainability: Status and Perspectives of Research on Urban Transformations," 2016. 
differently by their various stakeholders" 28 and this paper agrees that a broad pool of actors and stakeholders has been a great source of knowledge for the SATURN project objectives. The SATURN project is heavily based on a series of stakeholder engagement workshops, dealing with mapping, analysis, management, visioning and capacity building. Observations and outputs from workshops conducted in both the TMV and the UFGN case studies indicate that local actors are very significant to the successful delivery of "systemic change". Both TVW and UFGN aimed to build on stakeholder knowledge in order to improve the understanding and management process of landscape planning in the area. Following a series of hands-on online workshops, the participants were asked to communicate their goals, identify their own stakeholders (for their individual projects), map them and draw the connections formed between them. The results have been eye-opening to the SATURN team as well as the case study representatives participating in the workshops. It has been revealed that communication between the representatives has allowed greater knowledge sharing between them. It is agreed that "no single stakeholder has total knowledge of the system; [...]. For this reason, diversity is not just desirable but essential to generating a collective understanding of the system." 29 What the TVW and UFGN have demonstrated is that the process of stakeholder mapping, analysis and engagement has opened up ideas for new actions related to each project's goals and has eventually led to the identification of what extra is needed and how structure and governance can change in order to achieve it.

The Tame Valley Wetlands case study started by an initial evaluation of the broad landscape of the valley (Figure 4) helping to understand the scale of the open and green spaces as well as existing settlements and therefore the vast number of stakeholders who have interests in the area. The workshops have highlighted the need for re-evaluation of the current communication methods and have demonstrated who are the most appropriate actors to engage with in order to achieve sustainable development in the area.

28. Dreier, Nabarro and Nelson, Systems Leadership for Sustainable Development: Strategies for Achieving Systemic Change, 2019.

29. Ibid. 

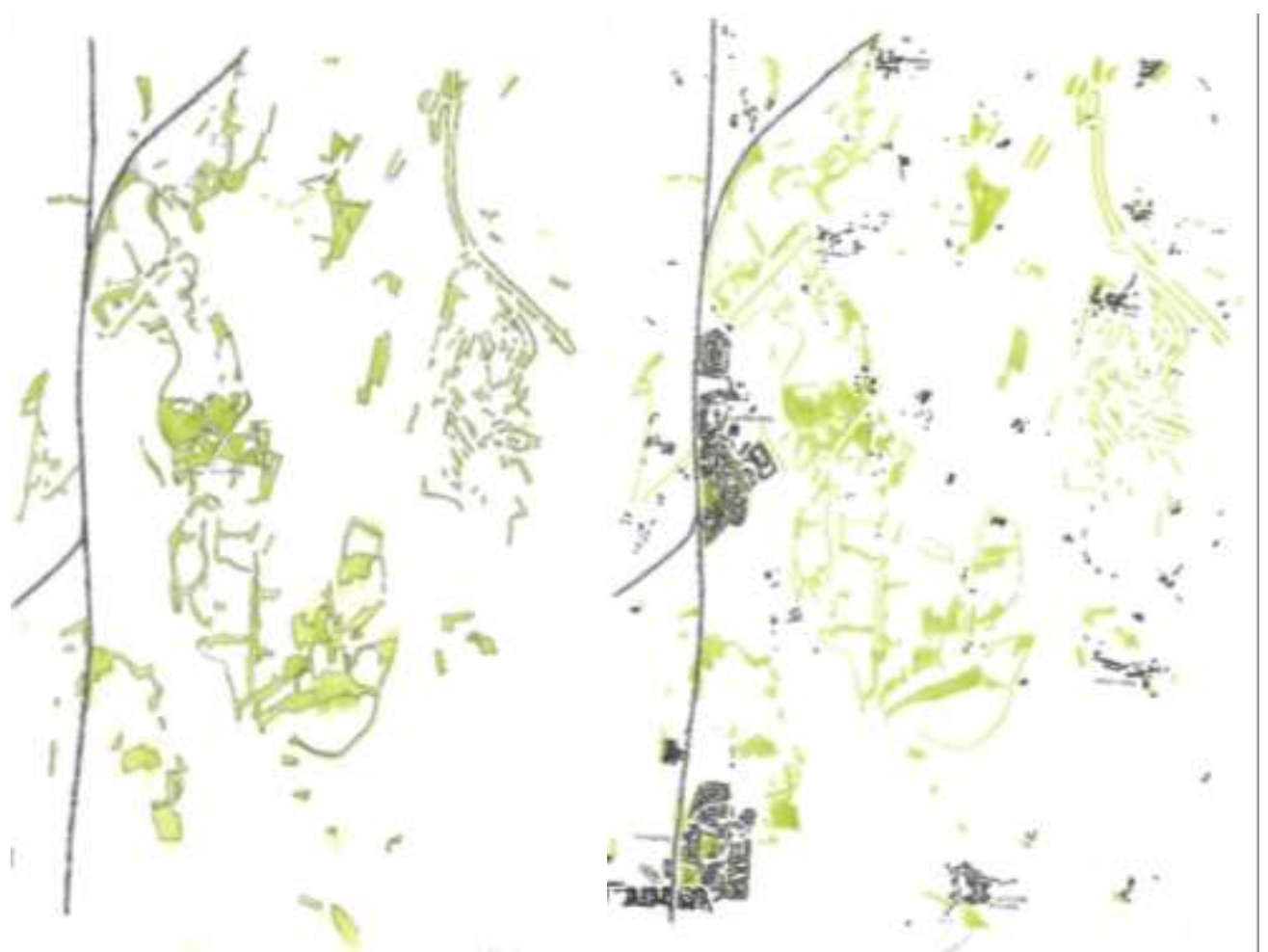

Figure 4. Diagrammatic Drawing Depicting the Current Situation of Green Spaces and Settlements around the Tame Valley, West Midlands UK

In addition, the workshops focusing on the Tame Valley Wetlands area, identified the lack of a broader vision that will support both bottom up initiatives and top down approaches, revealing the issue of communication. Despite the initiatives and good efforts of the governmental stakeholders in the area as well as the calls for actions from the various institutions and individual stakeholders, strong communication has been a challenge, creating several hurdles in the route to a behavioural and systemic transformation. The workshops have revealed that some less influential parties are in close communication, but usually not in strong, decision focused positions and decision-making stakeholders are not interested or do not have the capability to follow all the interesting initiatives happening in the area.

The chance to experience and work with the UFGN has revealed many hidden beneficiaries of the area who had either not been identified or not thought relevant for the scheme's goals. The UFGN has identified itself as a group providing support to the community, not just by growing plants and vegetables, but by "growing people" using the farming activities as both mental health support as well as a community bonding method. During the workshops, key outputs were recognised; the need for evaluation of the landscape, the recognition of the barriers in the area and the number of challenges in which the case study needs support from the city council. Routes of collaboration and ways to engage with several stakeholders the group was not possible to engage before, have also been discussed. The stakeholder engagement process has been of greater benefit than originally anticipated, helping the participants to understand that great initiatives 
need to be disseminated, that they also need great collaborators if they are to change some of the governance issues they face and support the transformation of their city and region.

\section{Discussion}

This paper has explored some of the pioneering schemes dealing with governance and decision making in strategic scale and has revealed six necessary steps that cannot be missed or overlooked to successfully achieve systemic change in cities and regions. All key actions presented here, Design, Policy, Decision Making, Governance, Stakeholder Engagement and Communication have been found fundamental in the way a system operates and therefore crucial when a transformation is needed. Having established that a systemic change is perhaps the only way to a zero-carbon future, the paper points out that a truly successful change of a regional system requires the re-evaluation and potential transformation of all the key actions. Even though current practice often approaches these steps in isolation or addresses them individually, the vision for a sustainable future and the requirement of behavioural change calls for a holistic approach. The interrelation of the six steps towards systemic change, from a landscape design and planning perspective, is apparent and any exclusion of one or the other will result to difficulties achieving systemic change.

To fully embrace a systemic change at a city and regional scale we not only need a great inspirational design, a set of generic policy rules and the willingness from the decision makers to change the way the governance operates, we also need behavioural change. Systemic change is a test of how well, we can change our behaviours and bad habits, and therefore to achieve this and have effective outcomes, it is necessary to engage with every and all stakeholders and start a collaborative process with them.

\section{Conclusions}

The significance of resilient, green and healthy cities is evident. Especially in a post pandemic (COVID-19) world, the necessity of access to nature, proximity to open spaces and the ability to adopt a healthier lifestyle seems a more future proof option for urban communities. This paper suggests that fully sustainable cities and regions cannot be created successfully if residents, decision makers and stakeholders do not change the way they operate and live. A behavioural and systemic change is necessary across all levels if we are to achieve resilience on a large scale.

The key actions of this paper are all important elements of systemic change on a spatial context. The need for all of these to work together has also been emphasised. A new policy cannot function without changing the decision-making process, and innovative design ideas cannot be delivered if not communicated to the stakeholders on the ground. Multidisciplinarity and cross-silo approaches are 
key in the fight against a changing climate, but landscape architecture and planning are great vehicles to achieve systemic change and they support concept and delivery. The establishment of a cross sectoral, interdisciplinary and environmentfocused project framework, supported by policies and legislation, can make a real difference in the way in which professional practice and politics deliver resilient concepts at a strategic level. However, a new way of thinking in design, policy or governance is not enough if these disciplines act in isolation. The breakthrough comes when each discipline collaborates with the aim to future proof our cities and regions. The key actions revealed by the landscape-led strategic schemes on this paper demonstrate how putting the landscape at the core of a development can create new concepts and raise aspirations for the future of our urban and rural environments. The paper suggests that landscape design is a powerful driver towards a net zero carbon transition, whilst at the same time can enhance social and landscape identity and boost the economy of a region. Through design, professionals and the public can better understand, test and evaluate their surrounding landscapes and imagine how their behavioural changes will result in a sustainable community to live in.

\section{Acknowledgments}

The author wants to thank all the stakeholders at the Room for the River, the West Midlands National Park, Tame Valley Wetlands Partnership, Social Farms and Gardens, SATURN and EIT Climate-KIC for their contribution to this research.

\section{Bibliography}

Angheloiu, C. and M. Tennant. "Urban Futures: Systemic or System Changing Interventions? A Literature Review Using Meadows' Leverage Points as Analytical Framework." Cities 104 (2020): 102808.

Bai, X., R. J. Dawson, D. Ürge-Vorsatz, G. C. Delgado, A. S. Barau, S. Dhakal, et al. Six Research Priorities for Cities and Climate Change. Nature Publishing Group 555 (2018): 23-25.

Blühdorn, I. "Sustaining the Unsustainable: Symbolic Politics and the Politics of Simulation." Environmental Politics 16, no. 2 (2007): 251-275.

Bulkeley, H. Cities and Climate Change. Abigdon: Routledge, 2013.

Consortium, S. SATURN Conference, Workshop, Exhibition. K. Moore and A. Nikologianni. Birmingham, UK: Birmingham City University, 2019.

Design Council. A Design-Led Approach to Infrastructure. Cabe, 2012.

Dreier, L., D. Nabarro and J. Nelson. Systems Leadership for Sustainable Development: Strategies for Achieving Systemic Change. USA: Harvard Kennedy School, 2019.

Gorissen, L., F. Spira, E. Meynaerts, P. Valkering and N. Frantzeskaki. "Moving Towards Systemic Change? Investigating Acceleration Dynamics of Urban Sustainability Transitions in the Belgian City of Genk.” Journal of Cleaner Production 173 (2018): 171-185. 
Masson, V., C. Marchadier, L. Adolphe, R. Aguejdad, P. Avner, M. Bonhomme, et al. "Adapting Cities to Climate Change: A Systemic Modelling Approach." Urban Climate 10 (2014): 407-429.

Nijhuis, S. and D. Jauslin. Urban Landscape Infrastructures. Designing Operative Landscape Structures for the Built Environment." Research in Urbanism Series 3 (2015): 13-34.

Nijhuis, S., D. Jauslin and C. De Vries. Flowscapes: Infrastructure as landscape, landscape as infrastructure. Graduation Lab Landscape Architecture 2012/2013. Delft, The Netherlands: Delft University of Technology, 2012.

Nikologianni, A. The Role of Low Carbon, Spatial Quality and Drawings in LandscapeBased Regional Strategies. Birmingham, U.K.: Birmingham City University, 2018.

Nikologianni, A., K. Moore and P. J. Larkham. "Making Sustainable Regional Design Strategies Successful." Sustainability 11, no. 4 (2019): 1-20.

Nikologianni, A., A. Betta, A. Pianegonda, S. Favargiotti, K. Moore, N. Grayson, et al. "New Integrated Approaches to Climate Emergency Landscape Strategies: The Case of Pan-European SATURN Project.” Sustainability 12, no. 20 (2020).

Ostberg, S., L. R. Boysen, S. Schaphoff, W. Lucht and D. and Gerten. "The Biosphere Under Potential Paris Outcomes." Earth's Future 6 (2018): 23-39.

Papa, R., A. Galderisi, M. C. Vigo Majello and E. Saretta. "Smart and Resilient Cities. A Systemic Approach for Developing Cross-Sectoral Strategies in the Face of Climate Change." TeMA Journal of Land Use, Mobility and Environment 8, no. 1 (2015): 1949.

Sijmons, D., Y. Feddes, E. Luiten, F. Feddes, M. Nolden and J. Bosch. Room for the River: Safe and Attractive landscapes. The Netherdlands: Blauwdruk, 2017.

von Wirth, T., L. Fuenfschilling, N. Frantzeskaki and L. Coenen. "Impacts of Urban Living Labs on Sustainability Transitions: Mechanisms and Strategies for Systemic Change Through Experimentation." European Planning Studies 27, no. 2 (2019): 229-257.

West Midlands Combined Authority - WMCA. WMCA signs up to West Midlands National Park. West Midlands, UK: WMCA, 2020.

Wolfram, M., N. Frantzeskaki and S. Maschmeyer. "Cities, Systems and Sustainability: Status and Perspectives of Research on Urban Transformations." Current Opinion in Environmental Sustainability 22 (2016): 18-25. 


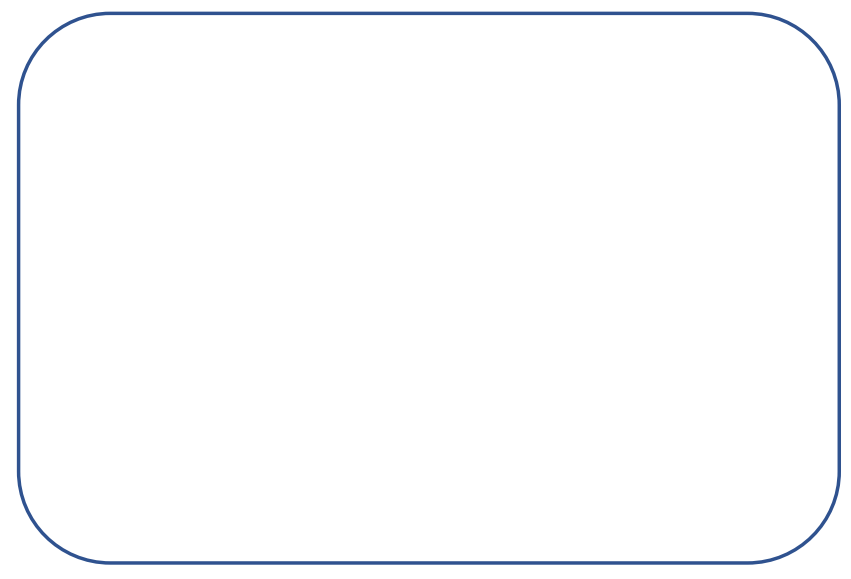

